\title{
Effect of the Type of Curing on the Corrosion Behavior of Concrete Exposed to Urban and Marine Environment
}

\author{
Miguel Angel Baltazar-Zamora, Sabino Márquez-Montero, Laura Landa-Ruiz, René Croche, Oscar \\ López-Yza
}

\begin{abstract}
This study analyzes the electrochemical behavior of AISI 1018 steel as reinforcement in concrete exposed to the Xalapa city (urban environment) and seawater (marine environment). Two concrete mixtures were made, with ratio w/c of 0.45 and 0.65 , according to the method of ACI 211.1. The specimens underwent three types of curing, the first was submerged in water for 27 days as indicated by the ONNCCE regulations, the second was cured as it is done on oeuvre (moisturizing the elements in the morning and in the afternoon) and the third one exposing to the environment (without applying water), before placing them in the exposition environment. The results of more than 340 days of monitoring of $E_{\text {corr }}$ and $I_{\text {corr }}$ demonstrate that the marine environment is the most aggressive in the corrosion of reinforced concrete, with a better performance of the concrete of ratio $\mathrm{w} / \mathrm{c}=0.45$ and with a curing according to normative.
\end{abstract}

Index Terms-Curing Type, Concrete, Corrosion, Urban Environment, Marine Environment.

\section{INTRODUCTION}

According to the literature it is known that one of the main economic problems of countries and in the process of development is the deterioration of reinforced concrete structures such as bridges, docks, buildings among others, considered to the corrosion that appears in the steel of reinforcement like the main cause of said deteriorations [13]. In first world countries where a systematic process of evaluation of the structures is carried out, figures of billions of dollars of cost have been reported to solve damages caused by this phenomenon [4-6].

Exist innumerable national and international works that board this problematic where this phenomenon is studied, and there are proposals considered as preventive as well as corrective and sustainable, using agroindustrial wastes such as sugar cane bagasse ash as a partial substitute for Portland cement, to improve the corrosion resistance of concrete [78], due to its pozzolanic properties [9].

Published on January 24, 2020.

M. A. Baltazar-Zamora is Research Professor of Universidad Veracruzana, Facultad de Ingeniería Civil - Xalapa, Xalapa, Veracruz, México (email: mbaltazar@uv.mx)

S. Márquez-Montero is Research Professor of Universidad Veracruzana, Facultad de Ingeniería Civil - Xalapa, Xalapa, Veracruz, México (email: smarquez@uv.mx)

L. Landa-Ruiz is Academic Technician of Universidad Veracruzana, Facultad de Ingeniería Civil - Xalapa, Xalapa, Veracruz, México (email: lalanda@uv.mx)

R. Croche is Research Professor of Universidad Veracruzana, Facultad de Ingeniería Mecánica y Eléctrica - Xalapa, Xalapa, Veracruz, México (email: recroche@uv.mx)

O. López-Yza is Academic Technician of Universidad Veracruzana, Facultad de Ingeniería Mecánica y Eléctrica - Xalapa, Xalapa, Veracruz, México (email: oslopez@uv.mx)
The present written addresses the problem with the idea of simulating in the laboratory the real conditions that builders face in the field, in this sense, it was considered to study concrete specimens with different types of curing, a curing according how is established in the normative of the ONNCCE, the second one a curing as it is commonly carried in the works where there is no quality control, which is humidify in the mornings and afternoons and the third one the most critical that would be without any cure, these specimens were made with two mixtures of different quality, ratio w/c of 0.45 and 0.65 , subjecting them to two means, urban (environment of the City of Xalapa) and to a marine environment (seawater).

While there exist regulations, and extensive literature indicating the importance of curing in the process of setting of concrete, unfortunately, the variables contemplated for this work are very common in real life, it is also true that that there are few jobs that try to study the effect on the corrosion behavior of the reinforcing steel caused by the type of curing or lack thereof are counted, and exposure environments of carbonation and aggressive ions such as chlorides. The objective of this writing is to analyze the results of corrosion potentials $\mathrm{E}_{\text {corr }}$ and corrosion kinetics or corrosion rate $\mathrm{I}_{\text {corr }}$ after more than 340 days of exposure to the media, urban and marine environment, determining the influence of the contact medium, the concrete quality and the type of curing in the corrosion process of the reinforcing steel, main variables that influence the durability of reinforced concrete structures according to the world community.

\section{MATERIALS AND METHODS}

\section{A. Materials}

\section{1) Physical characteristics of aggregates.}

The method used to calculate the proportion was that of ACI 211.1 [10], which is based on the physical characteristics of the materials, for the elaboration of the concrete mix preparation it was used natural aggregates which were determined their physical properties all according to ONNCCE standards, see Table I.

TABLE I: SUMMARY OF RESULTS OF THE CHARACTERIZATION OF THE AGGREGATES

\begin{tabular}{lcc}
\hline \hline Physical properties of materials & $\begin{array}{c}\text { Coarse } \\
\text { aggregate }\end{array}$ & $\begin{array}{c}\text { Fine } \\
\text { aggregate }\end{array}$ \\
\hline Specific Mass (MES) $\mathrm{g} / \mathrm{cm}^{3}$ & 2.32 & 2.66 \\
\hline Bulk Volumetric Mass (BVM) $\mathrm{Kg} / \mathrm{cm}^{3}$ & 1380 & - \\
\hline Absorption (\%) & 4 & 3.80 \\
\hline Module of Fineness & - & 2.70 \\
\hline Maximum Size Nominal (TMN) & $3 / 4 "$ & - \\
\hline \hline
\end{tabular}




\section{2) Proportion of concrete mixes}

For the present work was used a portland cement type CPC 30R, and water, were made two concrete mixtures, $\mathrm{w} / \mathrm{c}=0.45$ and $\mathrm{w} / \mathrm{c}=0.65$ ratio. The dosage for each mixture is shown in Table II.

TABLE II: DOSAGE OF CONCRETE MIXTURES IN KG FOR $1 \mathrm{M}^{3}$

\begin{tabular}{lcc}
\hline \multicolumn{1}{c}{ Materials } & $\begin{array}{c}\mathrm{w} / \mathrm{c}=0.45 \\
\left(\mathrm{~kg} / \mathrm{m}^{3}\right) \text { ratio }\end{array}$ & $\begin{array}{c}\mathrm{w} / \mathrm{c}=0.65 \\
\left(\mathrm{~kg} / \mathrm{m}^{3}\right) \text { ratio }\end{array}$ \\
\hline Water & 178 & 178 \\
\hline Cement & 456 & 316 \\
\hline Coarse aggregate & 913 & 913 \\
\hline Fine aggregate & 863 & 1012 \\
\hline Additive (accelerant) & $2 \%$ wt. CPC & $2 \%$ wt. CPC \\
& $30 \mathrm{R}$ & $30 \mathrm{R}$ \\
\hline \hline
\end{tabular}

\section{B. Method}

1) Concrete characterization in a fresh and hardened state

To determine the characteristics of fresh concrete and its mechanical strength, studies were conducted according to the ONNCCE and ASTM standards, see Table III.

TABLE III: PHYSICAL PROPERTIES OF CONCRETE MIXTURES

\begin{tabular}{lcc}
\hline \hline Parameter & w/c $=0.45$ ratio & w/c $=0.65 \mathrm{ratio}$ \\
\hline Slump [11] & $7.0 \mathrm{~cm}$ & $6.0 \mathrm{~cm}$ \\
Temperature [12] & $24.0^{\circ} \mathrm{C}$ & $23.5^{\circ} \mathrm{C}$ \\
Density [13] & $2346 \mathrm{~kg} / \mathrm{m}^{3}$ & $2307 \mathrm{~kg} / \mathrm{m}^{3}$ \\
Compressive strength [14] & $395 \mathrm{~kg} / \mathrm{cm}^{2}$ & $245 \mathrm{~kg} / \mathrm{cm}^{2}$ \\
\hline \hline
\end{tabular}

\section{2) Characteristic and nomenclature of test specimens.}

In each specimen two steel bars of AISI 1018 were embedded, 3/8" diameter corrugated, reinforcing steel commonly used in reinforced concrete structures worldwide, one of the two rods were used as a working electrode (WE) and the other of auxiliary electrode (AE), and a standar copper-copper sulfate $\left(\mathrm{Cu} / \mathrm{CuSO}_{4}\right)$ as reference electrode (RE), for to use the technique of linear polarization resistance (LPR) as indicated by the ASTM-G59 standard [15], each of the bars were placed $5 \mathrm{~cm}$ paint at the top and $5 \mathrm{~cm}$ at the bottom, in order to delimit the area of exposure to corrosion of steel in concrete with a length of $5 \mathrm{~cm}$ (Fig. 1), experimental arrangement, which has been used in various investigations [16-19].
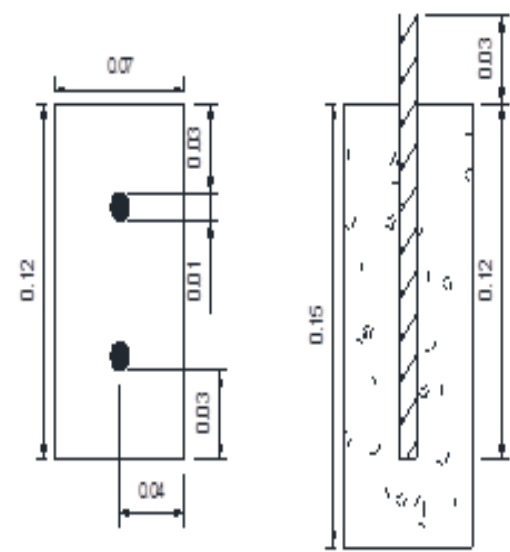

Fig. 1. Dimensions of study specimens $(\mathrm{cm})$

For the study specimens and according to the parameters to be evaluated, described and treated in the previous section, we proposed the nomenclature that shown in the following Table IV.
TABLE IV: NOMENCLATURE OF SPECIMENS FOR EVALUATION OF CORROSION

\begin{tabular}{lccc}
\hline \hline \multicolumn{4}{c}{ Nomenclature for each mixture } \\
$\mathrm{w} / \mathrm{c}=0.45$ & ratio & \multicolumn{2}{c}{$\mathrm{w} / \mathrm{c}=0.65$ ratio } \\
\hline $4 \mathrm{NU}$ & $4 \mathrm{NM}$ & $6 \mathrm{NU}$ & $6 \mathrm{NM}$ \\
$4 \mathrm{OU}$ & $6 \mathrm{OM}$ & $6 \mathrm{OU}$ & $6 \mathrm{OM}$ \\
$4 \mathrm{SU}$ & $4 \mathrm{SM}$ & $6 \mathrm{SU}$ & $6 \mathrm{SM}$ \\
\hline \hline
\end{tabular}

- 4 y 6 indicates the ratio w/c, 0.45 and 0.65 .

- $\mathrm{N}=$ curing according to the standard, $\mathrm{O}=$ Cured in situ and $\mathrm{S}=$ Without cured

- $\mathrm{U}=$ Urban environment (Cd. Xalapa) and $\mathrm{M}=$ Marine environment (seawater)

\section{RESUlTS AND DisCUSSION}

\section{A. Corrosion potential $\left(E_{\text {corr }}\right)$}

The specimens were monitored in accordance with ASTM C876-15 [20] as well as the interpretation of the results obtained by adding a further range as indicated in the literature [21], the above are summarized in Table V.

\begin{tabular}{cc} 
TABLE V: CORROSION POTENTIAL IN REINFORCED CONCRETE $\left(\mathrm{E}_{\mathrm{CORR}}\right)$ \\
\hline \hline \multicolumn{2}{c}{ Corrosion potentials $\mathrm{mV}$ vs Cu/CuSO} \\
\hline$<-500$ & Severe corrosion \\
$<-350$ & $90 \%$ Probability of Corrosion \\
-350 to -200 & Uncertainty \\
$>-200$ & $10 \%$ Probability of Corrosion \\
\hline \hline
\end{tabular}

\section{1) Behavior of $E_{\text {corr }}$ of specimens exposed to urban and marine environment}

In Fig. 2, we can see the graph, that after curing the specimens of $\mathrm{w} / \mathrm{c}=0.45$ and 0.65 ratio, exposed to the environment of the city of Xalapa, Ver. (Urban environment).

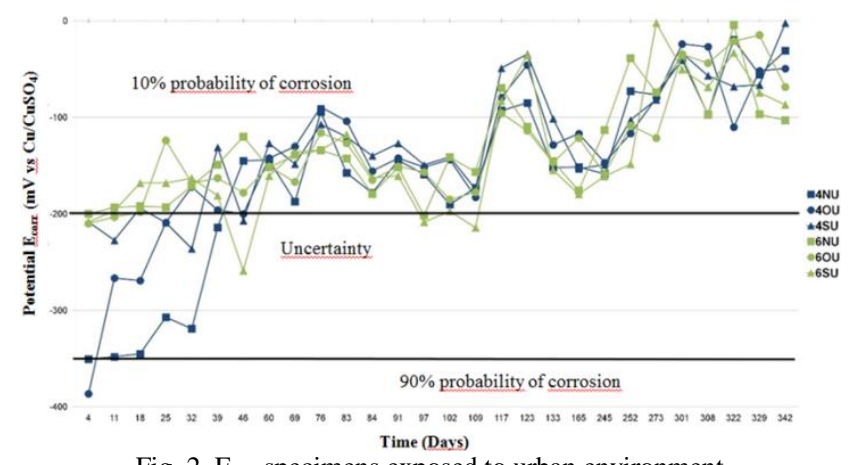

Fig. 2. $\mathrm{E}_{\mathrm{corr}}$ specimens exposed to urban environment

The specimens present after day 60 values of $E_{\text {corr }}$ more positive to $-200 \mathrm{mV}$, what it indicates according to the standar ASTM C-876-15, 10\% of probability of corrosion according to the norm, this trend was maintained until the end of the exposure time that was more than 340 days. It is not observed or cannot be distinguished in the behavior of the corrosion potential of $E_{\text {corr }}$, an influence of the type of curing and the relation with water/cement, having the six specimens a homogeneous behavior of passive or noncorrosive state.

In Fig. 3 it can be seen how the exposure in the marine environment evidence the temporal efficiency that concrete present of a lower relation with w/c, being more resistant to the aggressive environment as is sea water, presenting all specimens of relation $\mathrm{w} / \mathrm{c}=0.45$, values of $\mathrm{E}_{\mathrm{corr}}$, with a 
tendency to more positive values, going from $-300 \mathrm{mV}$ to $215 \mathrm{mV}$ from day 30 to 150 , what according to the norm ASTM C-876-15 indicates uncertainty of the presence of corrosion, but after day 160 the specimen 4SM presents an activation, with a tendency until the end of the monitoring of $E_{\text {corr }}$ more negative until reach to $-490 \mathrm{mV}$, the specimen with curing work $4 \mathrm{OM}$ presents on day 265 the trend towards more negative values reaching the end of values of $480 \mathrm{mV}$, the behavior is in the specimen with curing according to the norm, 4NM which until day 300 presents $\mathrm{E}_{\text {corr }}$ more negative than $-350 \mathrm{mV}$.

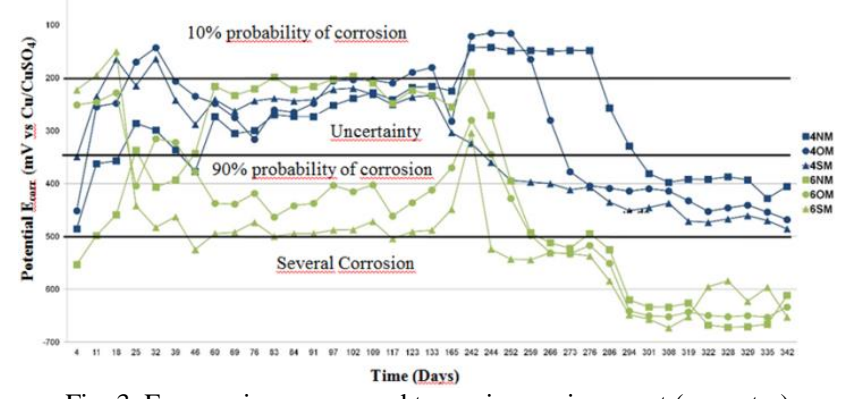

Fig. 3. $\mathrm{E}_{\mathrm{corr}}$ specimens exposed to marine environment (seawater)

For specimens made with a lower quality concrete o relation $\mathrm{w} / \mathrm{c}=0.65$, and with a poor cure, specimen $6 \mathrm{SM}$, they present a $90 \%$ of probability of corrosion form the first week of exposure to the marine environment, the benefit of curing is observed from the norm in this relation w/ c, 6NM presents until the day 150 values of $E_{\text {corr }}$ that indicate uncertainty of corrosion, with the passage of time this benefit by proper curing is lost, the same as the relation specimens $\mathrm{w} / \mathrm{c}=0.45$, presenting potential values after day 220 that indicate $90 \%$ probability of corrosion, to behave unfavorably as well as specimens cured on work and without curing (6OM y $6 \mathrm{SM})$, presenting values that indicate the presence of severe corrosion, from day 260 to the end of monitoring, day 342.

\section{B. Kinetics of Corrosion (Icorr)}

The results of the corrosion kinetics $\mathrm{I}_{\text {corr }}$ were interpreted according to the criterion of the DURAR Network Manual [22], see Table VI.

TABLE VI: LEVEL OF CORROSION ACCORDING TO I $\mathrm{I}_{\text {CORR }}$

\begin{tabular}{cc}
\hline \hline Corrosion rate $\left(\mathrm{I}_{\text {corr }}\right) \mu \mathrm{A} / \mathrm{cm}^{2}$ & Level of Corrosion \\
\hline$<0.1$ & Despicable \\
$0.1-0.5$ & Moderate \\
$0.5-1$ & High \\
$>1$ & Very high \\
\hline \hline
\end{tabular}

1) Behavior of $I_{\text {corr }}$ of specimens exposed to urban and marine environment

Figure 4 shows the behavior of the corrosion rate, $\mathrm{I}_{\text {corr }}$ of the specimens of both relations w/c, exposed to the urban environment of the City of Xalapa, Ver., Mexico.

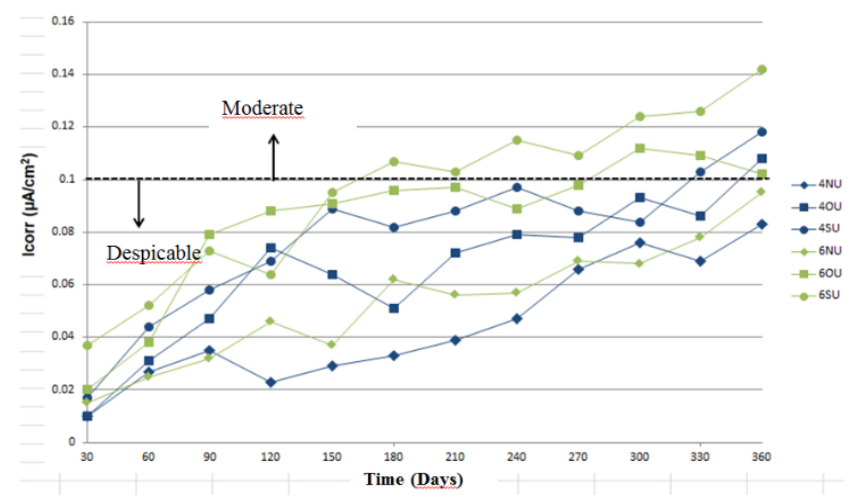

Fig. 4. $\mathrm{I}_{\text {corr }}$ of the specimens exposed to the urban environment

When $I_{\text {corr }}$ was evaluated by the technique of RPL, the behavior observed in the corrosion potentials of all specimens exposed to said medium is reaffirmed. It has to be all specimens that made with a concrete of better quality that which are of relation $w / c=0.45$, they have a good performance against corrosion during more than 342 days of exposure, highlighting the specimen that was cured according to the standar 4NU, 27 days submerged in water, as presented throughout the period values of $\mathrm{I}_{\text {corr }}$ below 0.1 $\mu \mathrm{A} / \mathrm{cm}^{2}$ what is indicated a despicable level of corrosion according to the DURAR Network Manual, followed by a curing applied as it is done on work, 4OU, presenting values of $I_{\text {corr }}$ below of $0.1 \mu \mathrm{A} / \mathrm{cm}^{2}$ until the day 330 , to activate the system and present at the last monitoring an $\mathrm{I}_{\text {corr }}$ greater than $0.1 \mu \mathrm{A} / \mathrm{cm}^{2}$, which indicates a moderate level of corrosion, so also the specimen without curing $4 \mathrm{SU}$, which presented a despicable level of corrosion until day 300, to present a moderate level of corrosion in the last 60 days of exposure. In the case of relation specimens $\mathrm{w} / \mathrm{c}=0.65$, the specimen with standard cure $6 \mathrm{NU}$, presented values of $\mathrm{I}_{\text {corr }}$ slightly higher than the specimen $4 \mathrm{NU}$, but all until the end of monitoring below to $0.1 \mu \mathrm{A} / \mathrm{cm}^{2}$, indicating a despicable level of corrosion, however the specimen $6 \mathrm{OU}$ presented a despicable level of corrosion only until day 270 , from there until the end of the monitoring show a moderate level of corrosion, with values of $I_{\text {corr }}$ higher than $0.1 \mu \mathrm{A} / \mathrm{cm}^{2}$, observing the influence of the type of cure, so too the specimen 6SU, which was activated from day 180 presenting values greater than greater than $0.1 \mu \mathrm{A} / \mathrm{cm}^{2}$, with a tendency over time to increase, reaching up 0.14 of $\mathrm{I}_{\text {corr }}$, at the end of the exposure time. The analyzed results of $I_{\text {corr }}$ of concrete exposed to the environment of the City of Xalapa, Ver., coincided with what is reported in the literature [23], being this a little aggressive environment compared to a marine environment.

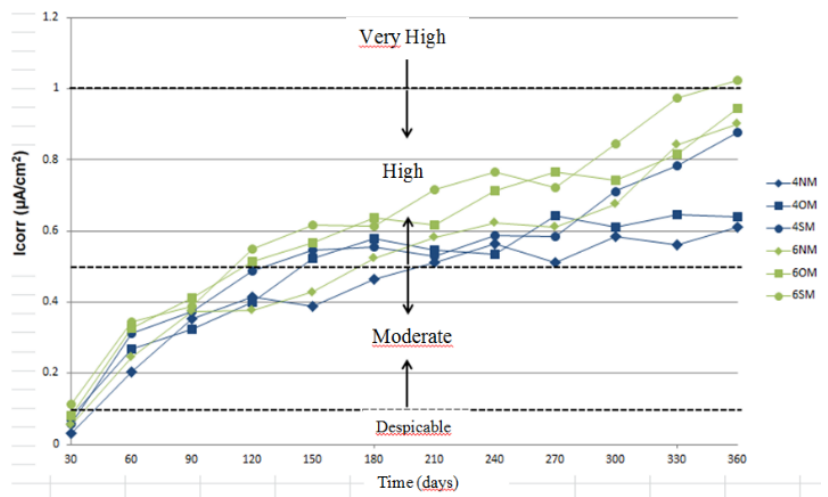

Fig. 5. $\mathrm{I}_{\text {corr }}$ specimens exposed to marine environment (seawater) 
Fig. 5 presents the $\mathrm{I}_{\text {corr }}$ results of the study specimens exposed in a marine environment (seawater). It can be seen unlike the urban environment, that the marine environment is very aggressive, which confirms what is mentioned in the literature [24]. But what needs to be analyzed is how the corrosion kinetics behavior of each specimen, highlighting the importance of concrete quality and type of curing, that as indicated by the concrete quality community or the relation w/c ratio used, the concrete will present important mechanical and durability characteristics such as resistivity and ultrasonic pulse, which correlates with corrosion resistance [25]. Although the aggressiveness of the medium is observed from the first 60 days of exposure presenting all specimens values greater than $0.2 \mu \mathrm{A} / \mathrm{cm}^{2}$, it can be seen relatively better performance of low water cement specimens, those of 0.45 , highlighting whether it can be considered that way, the specimen cured with norm 4NM which presented $I_{\text {corr }}$ below $0.5 \mu \mathrm{A} / \mathrm{cm}^{2}$ until day 180 , moderate corrosion level, followed by specimens with curing type in Work and Without Curing, which kept the level of corrosion moderate, until before the 150 days of exposure with lower values than $0.5 \mu \mathrm{A} / \mathrm{cm}^{2}$. Analyzing the specimens of $w / c=0.65$ relation, it is observed that since day 120 they have a high level of corrosion, finished at the end of monitoring the specimen without curing 6SM, with an $I_{\text {corr }}$ greater than $1 \mu \mathrm{A} / \mathrm{cm}^{2}$, which indicates a very high level of corrosion, followed by the 6OM, 6NM y el 4SM specimen. Confirming the behavior of $\mathrm{E}_{\mathrm{corr}}$ corrosion potentials in Fig. 3.

\section{CONCLUSION}

It was shown that the quality of the concrete and the type of curing are the most important factors in the behavior of the corrosion kinetics of reinforced concrete with AISI 1018 steel.

When said element is exposed to an environment as aggressive as it is marine environment, in this case seawater, it was observed that concrete low and medium ratio w/c ( 0.45 y 0.65$)$ cured according to standard have relatively higher corrosion resistance in a marine environment, than concrete with poor curing or no curing.

It was also observed how the urban environment of the City of Xalapa is less aggressive than the marine environment, but that is an environment where corrosion occurs and that the quality of the concrete as well as the type of curing would have to be considered mainly in the works of self-construction type (Works without Quality Control of Hydraulic Concrete Processing).

\section{ACKNOWLEDGMENT}

MA Baltazar-Zamora, et. al., thank PRODEP for the support granted by the SEP, the Academicians UV-CA-458 "Sustainability and Durability of Materials for Civil Infrastructure" under the Call 2018 for Strengthening Academic Bodies with IDCA 28593.

\section{REFERENCES}

[1] G. Santiago-Hurtado, M.A. Baltazar-Zamora, R. Galván-Martínez, L D. López L, F. Zapata G, P- Zambrano, C. Gaona-Tiburcio, F. Almeraya-Calderón. (2016). Electrochemical Evaluation of Reinforcement Concrete Exposed to Soil Type SP Contaminated with Sulphates. International Journal of Electrochemical Science, 11:6, pp. 4850-4864.

[2] A. Landa-Gómez, R. Croche B, S. Márquez M, R. Villegas A, H.A. Ariza-Figueroa, F.H. Estupiñán-López, C. Gaona-Tiburcio, F. Almeraya-Calderón, M.A. Baltazar-Zamora. (2018). Corrosion Behavior 304 and 316 Stainless Steel as Reinforcement in Sustainable Concrete Based on Sugar Cane Bagasse Ash Exposed to $\mathrm{Na}_{2} \mathrm{SO}_{4}$. ECS Transactions, 84:1, pp. 179-188.

[3] G. Santiago-Hurtado, M.A. Baltazar-Zamora, J. Olguín-Coca, L. D. López L, R. Galván-Martínez, A. Ríos-Juárez, C. Gaona-Tiburcio, F. Almeraya-Calderón. (2016). Electrochemical Evaluation of a Stainless Steel as Reinforcement in Sustainable Concrete Exposed to Chlorides. International Journal of Electrochemical Science, 11:4, pp. 2994-3006.

[4] M.A. Baltazar-Zamora, D.M. Bastidas, G. Santiago-Hurtado, J.M. Mendoza-Rangel, C. Gaona-Tiburcio, J.M. Bastidas, F. AlmerayaCalderón. (2019). Effect of Silica Fume and Fly Ash Admixtures on the Corrosion Behavior of AISI 304 Embedded in Concrete Exposed in $3.5 \% \mathrm{NaCl}$ Solution. Materials (Basel), 12:23, pp. 1-13.

[5] T. Bellezze, M. Malavolta, A. Quaranta, N. Ruffini, G. Roventi. (2006). Corrosion behaviour in concrete of three differently galvanized steel bars, Cement and Concrete Composites, 28:3, pp. 246-255.

[6] M.A. Baltazar-Zamora et. al. (2012). Efficiency of Galvanized Steel Embedded in Concrete Previously Contaminated with 2, 3 and $4 \%$ of $\mathrm{NaCl}$. International Journal of Electrochemical Science, 7:4, pp. 2997-3007.

[7] Aldo Landa-Gómez, S. Castillo Aguilar, J.A. Reyes Jimenez, R. Villegas Apaez, Jose. A. Cabral-Miramontes, C. Gaona Tiburcio, F. Almeraya, Miguel Angel Baltazar-Zamora. (2018). Evaluation of the Corrosion of AISI 304 Stainless Steel Embedded in Sustainable Concrete with High Volumes of Scba-SF Exposed in Marine Environment. ECS Meeting Abstracts, MA2018-02, pp. 587.

[8] Aldo Landa-Gómez, R. Croche B, O.M. López Yza, R. GalvánMartínez, J.A. Cabral-Miramontes, C. Gaona Tiburcio, F. Almeraya, Miguel Angel Baltazar-Zamora. (2018). Corrosion Behavior of AISI 316 Stainless Steel as Reinforcement in Ternary Sustainable Concrete Based on Scba-SF Exposed in Seawater. ECS Meeting Abstracts, MA2018-02, pp. 584.

[9] O. Ojeda-Farías, J.M. Mendoza-Rangel, M.A. Baltazar-Zamora. (2018). Influence of sugar cane bagasse ash inclusion on compacting, $\mathrm{CBR}$ and unconfined compressive strength of a subgrade granular material. Revista ALCONPAT, 8:2, pp. 194-208.

[10] ACI. Provision of mixtures, normal concrete, heavy and massive ACI 211.1, p. 29. Ed. IMCYC, México (2004).

[11] NMX-C-156-ONNCCE-2010: Determinación del revenimiento en el concreto fresco. ONNCCE S.C., México, (2010).

[12] ASTM C 1064/C1064M-08-Standard Test Method for Temperature of Freshly Mixed Hydraulic-426 Cement Concrete; ASTM International, West Conshohocken, PA, 2008, www.astm.org

[13] NMX-C-162-ONNCCE-2014: Determinación de la masa unitaria, cálculo del rendimiento y contenido de aire del concreto fresco por el método gravimétrico., ONNCCE S.C., México, (2014).

[14] NMX-C-083-ONNCCE-2014: Determinación de la resistencia a la compresión de especímenes - Método de prueba, ONNCCE S.C., México, (2014).

[15] ASTM G 59-97 (2014) - Standard Test Method for Conducting Potentiodynamic Polarization Resistance Measurements, ASTM International, West Conshohocken, PA, 2014, www.astm.org

[16] Miguel Angel Baltazar-Zamora, José Manuel Mendoza-Rangel, René Croche, Citlalli Gaona-Tiburcio, Cindy Hernández, Luis López, Francisco Olguín, Facundo Almeraya-Calderón. (2019). Corrosion Behavior of Galvanized Steel Embedded in Concrete Exposed to Soil Type MH Contaminated with Chlorides. Frontiers in Materials, 6, pp. $1-12$.

[17] M. Criado, D.M. Bastidas, S. Fajardo, A. Fernández-Jiménez, J.M. Bastidas. (2011). Corrosion behaviour of a new low-nickel stainless steel embedded in activated fly ash mortars. Cement and Concrete Composites, 33, pp. 644-652.

[18] M.A. Baltazar-Zamora, G. Santiago-Hurtado, C. Gaona-Tiburcio et. al. (2012). Evaluation of the corrosion at early age in reinforced concrete exposed to sulfates. International Journal of Electrochemical Science, 7:1, pp. 588-600. 
[19] G. Santiago-Hurtado, M.A. Baltazar-Zamora, A. Galindo D, J.A Cabral M, F.H. Estupiñán L., P. Zambrano Robledo, C. GaonaTiburcio. (2013). Anticorrosive Efficiency of Primer Applied in Carbon Steel AISI 1018 as Reinforcement in a Soil Type MH. International Journal of Electrochemical Science, 8:6, pp. 8490-8501.

[20] ASTM C 876-15 (2015) -Standard Test Method for Corrosion Potentials of Uncoated Reinforcing steel in Concrete, ASTM International, West Conshohocken, PA, 2015, www.astm.org

[21] H.W. Song, V. Saraswathy. (2007). Corrosion Monitoring of Reinforced Concrete Structures - A Review. International Journal of Electrochemical Science, 2:1, pp. 1-28.

[22] O. Troconis De Rincón et. al., Manual de Inspección, Evaluación y Diagnóstico de Corrosión en Estructuras de Hormigón Armado, p. 134. Red DURAR. CYTED. Venezuela (1997)

[23] O. Troconis de Rincón et. al., (2016). Reinforced Concrete Durability in Marine Environments DURACON Project: Long-Term Exposure Corrosion, 72:6, pp. 824-833.
[24] M.A. Baltazar-Zamora, G. Santiago-Hurtado, V.M. Moreno L, R. Croche B, M. de la Garza, F. Estupiñan L, P. Zambrano R., C. GaonaTiburcio. (2016). Electrochemical Behaviour of Galvanized Stee Embedded in Concrete Exposed to Sand Contaminated with $\mathrm{NaCl}$ International Journal of Electrochemical Science, 11:12, pp. 1030610319.

[25] A. Landa-Gómez, R. Croche B, S. Márquez-Montero, R. GalvanMartínez, C. Gaona-Tiburcio, F. Almeraya-Calderón, M.A. BaltazarZamora. (2018). Correlation of Compression Resistance and Rupture Module of a Concrete of Ratio w/c $=0.50$ with the Corrosion Potential, Electrical Resistivity and Ultrasonic Pulse Speed. ECS Transactions, 84:1, 217-227. 